\title{
Synthesis, Characterisation, Crystal Structure and Anti-corrosion Studies of an Organotin(IV) Complex of 2-acetylpyridine 4-ethyl-3- thiosemicarbazone (LH): n-BuSn(L)Cl 2
}

\author{
N.N. Hazani ${ }^{1,2}$, N.N. Dzulkifli2 ${ }^{2}$, S.A.I.S.M. Ghazali², Y. Mohd ${ }^{1}$, Y. Farina ${ }^{3}$ and F. Ngatiman 4 \\ ${ }^{1}$ Faculty of Applied Sciences, Universiti Teknologi MARA, \\ 40450 Shah Alam, Selangor, Malaysia. \\ ${ }^{2}$ Faculty of Applied Sciences, Universiti Teknologi MARA, \\ Kuala Pilah Campus, 72000 Kuala Pilah, Negeri Sembilan, Malaysia. \\ ${ }^{3}$ Faculty of Science and Technology, Universiti Kebangsaan Malaysia, \\ 43600 Bangi, Selangor, Malaysia \\ ${ }^{4}$ Centre of Research and Instrumentation, Universiti Kebangsaan Malaysia, \\ 43600 Bangi, Selangor, Malaysia
}

\begin{abstract}
This study explored the possibility of Schiff-base ligand compound, 2-acetylpyridine 4-ethyl-3-

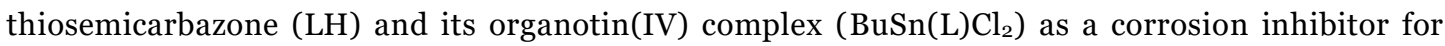
mild steel in $1 \mathrm{M}$ hydrochloric acid $(\mathrm{HCl})$ medium. The chemical structures of the synthesised compounds were confirmed by performing elemental analysis, FT-IR, UV-Vis, NMR spectroscopy, and X-ray crystallography diffraction study. The structure showed the LH served as a tridentate (N, N', S) donor to tin through its pyridyl, azomethine nitrogen, and thiolate sulphur. The corrosion inhibition characteristics of the free Schiff-base ligand and its organotin complex were studied by the standard weight loss method. They showed inhibition activity through adsorption, and this phenomenon was found to obey Langmuir adsorption isotherm. The inhibition efficiency of both compounds was found to increase as their concentration was increased from 1 to $3 \mathrm{mM}$, but the efficiency achieved with the tin complex was greater, being $98.98 \%$ at $3 \mathrm{mM}$ concentration.
\end{abstract}

Keywords: 2-acetylpyridine; butyltin(IV); corrosion inhibitor; thiosemicarbazone

\section{INTRODUCTION}

An industrial process such as acid pickling is an activity where the metals are immersed in acid media, especially hydrochloric acid, to remove scale and rust. After the scales are eliminated, the surfaces of the metal are exposed and react with the acid media, which causes metal dissolution. To solve this problem, corrosion inhibitors in a small amount are added into corrosive media to reduce the rate of metal dissolution by reducing the aggressiveness of acid media against the corrosion attack (Zaferani et al., 2013; Umoren and Solomon, 2017). An organic inhibitor acts as a good inhibitor among other corrosion inhibitors because it contains heteroatoms such as sulphur, nitrogen, and oxygen in addition to the presence of aromatic rings (Elenmike et al., 2017; Al-Amiery et al., 2013; Ebenso et al., 2010; Benhiba et al., 2017). The organic inhibitor acts through adsorption on metal surfaces by forming a layer which prevents the attack of acid media to metal surfaces (Khan et al., 2017; Manivel et al., 2014).

Thiosemicarbazone derivatives showed significant biological activity and other potential industrial applications (Yadav et al., 2014; Reis et al., 2011). The latest application is in finding new corrosion inhibitors

*Corresponding author's e-mail: nurnadia@ns.uitm.edu.my 
(Bisceglie et al., 2015). Many thiosemicarbazone derivative compounds are reported as an effective corrosion inhibitor in various media for different metals and alloys (Khaled et al., 2010; Goulart et al., 2013; Badr, 2009; Zhang et al., 2014; Ameer et al., 2000). Thiosemicarbazone is an organic compound containing nitrogen and sulphur atoms that have a potential site to adsorb on the metal surface which protects the metal surface from corrosion attack by acid media. The work of Ekpe et al., (1995) focused on the effect of 2-acetylpyridine-4-phenylthiosemicarbazone and 2-acetylpyridine-4-methylthiosemicarbazone as corrosion inhibitors on mild steel in 0.5, 0.1, 0.05, 0.01, and 0.005M HCl. Khaled et al. (2010) looked into the effect of $3^{-}$ pyridinecarboxaldehyde thiosemicarbazone on mild steel in $1 \mathrm{M} \mathrm{HCl}$. The authors also reported the study of inhibition efficiency by using carbon steel and sulphuric acid as media. Goulart et al. (2013) reported four thiosemicarbazone derivatives, 4-ethoxybenzaldehyde thiosemicarbazone, 4-hydroxybenzaldehyde thiosemicarbazone, 4-hydroxy-3-methoxybenzaldehyde thiosemicarbazone, and 2-pyridinecarboxaldehyde thiosemicarbazone as corrosion inhibitors towards carbon steel in $1 \mathrm{M} \mathrm{HCl}$ solution. On the other hand, Zhang et al. (2014) studied 4-methoxysalicylaldehyde thiosemicarbazone on carbon steel in $0.5 \mathrm{M} \quad \mathrm{H}_{2} \mathrm{SO}_{4}$ solution.

Tin or organotin complexes have attracted attention around the globe since the complexes provide a wide range of structural features and make them available in a diversity of applications (Singh and Bhandari, 2003). The tin complexes are important to biological activities such as antibacterial, antifungal, anticancer, antiviral, antiparasitic, anti-malarial and antiplasmodial (Kurniasih et al., 2015; Manju et al., 2011). The combination of thiosemicarbazone derivatives and tin ion to produce new anti-corrosion inhibitors is very challenging and has captured much attention of many researchers. It is reported that the anti-corrosion activity increases upon complexation with metal ions (Neha et al., 2015). Having an active centre which is more electronegative than iron makes the compounds capable of forming protective layers. Also, organotin is recognised for its biocidal behaviour, friction and wear reducing properties, as well as corrosioninhibiting characteristics (Rastogi et al., 2012).

In this paper, a novel organotin complex was synthesised by the reaction of butyltin(IV) trichloride with 2- acetylpyridine-4-ethyl-3-thiosemicarbazone (1:1 ratio). Both the ligand and the complex were characterised by an elemental analyser (CHNS), Fourier Transform Infrared Attenuated Total Reflection Spectroscopy (IRATR), Ultraviolet-Visible Spectroscopy (UV-Vis), Nuclear Magnetic Resonance (NMR), and X-ray crystallography diffraction study. Both compounds were also investigated for their efficacy in the corrosion inhibition of mild steel in $1 \mathrm{M} \mathrm{HCl}$ at ambient temperature $(303 \mathrm{~K})$ by using the classical weight loss technique.

\section{MATERIALS AND METHODS}

\section{A. Materials}

All chemicals used (2-acetylpyridine, 4-ethyl-3thiosemicarbazide, butyltin(IV) trichloride) were purchased from Sigma Aldrich, and solvents (ethanol, acetic acid, hydrochloric acid) were of analytical grade. All reagents were used without further purification. Mild steel was used in this study with the chemical composition of $\mathrm{C}-0.34 \%$, $\mathrm{Mn}-0.76 \%, \mathrm{P}-0.02 \%, \mathrm{Si}-0.3 \%$, and balance Fe. The mild steel sheet used was sized $2 \mathrm{~cm}$ x $2 \mathrm{~cm}$.

\section{B. Inhibitors}

\section{Synthesis of LH (Scheme 1)}

The LH was prepared by mixing an ethanoic solution of 2acetylpyridine (1mmol) and an ethanoic solution of 4-ethyl3 -thiosemicarbazide (1mmol). Then, a few drops of acetic acid were added to the mixture. The reaction mixture was refluxed for 2 hours at $60-70^{\circ} \mathrm{C}$ with constant stirring. After 2 hours, the solution was cooled at room temperature. The crystalline product was obtained by slow evaporation at room temperature. The crystalline product that formed was filtered and washed with cold ethanol and dried over anhydrous silica gel.

\section{Synthesis of BuSn(L)Cl2 (Scheme 2)}

The synthesised LH (1mmol) was dissolved in ethanol and the metal salt, butyltin(IV) trichloride (1mmol), was dissolved in distilled water. The metal salt was added 
stirring. The reaction mixture was continuously stirred for 4 hours. The product was then filtered and washed with cold ethanol. The precipitate formed was left to dry over silica gel. The filtrate was left dried at room temperature to get a yellowish crystal.<smiles>CC(=O)c1ccccn1</smiles>

2-acetylpyridine<smiles>CCNC(=S)NN</smiles>

4-ethyl-3-thiosemicarbazide<smiles>CCNC(=S)N/N=C(\C)c1ccccn1</smiles>

2-acetylpyridine 4-ethyl-3-thiosemicarbazone

Scheme 1. Synthetic route of LH<smiles>CCNC(=S)N/N=C(\C)c1ccccn1</smiles>

2-acetylpyridine 4-ethyl-3-thiosemicarbazone<smiles>[CH2+]CCC[Sn](Cl)(Cl)Cl</smiles>

butyltin trichloride<smiles>CCCC[As](Cl)(Cl)N1C=CC=C2C(C)=NN=C(NCC)S[N+]21</smiles>

2-acetylpyridine 4-ethyl-3thiosemicarbazone dichlorobutyltin

Scheme 2. Synthetic route of $\mathrm{BuSn}(\mathrm{L}) \mathrm{Cl}_{2}$

\section{Preparation of Stock Solution}

The acidic solution, $1 \mathrm{M}$ of analytical grade $37 \%$ hydrochloric acid $(\mathrm{HCl})$ was prepared by dilution with distilled water. The concentrations of the ligand and complex were prepared by dilution with distilled water from $1 \mathrm{mM}$ to $3 \mathrm{mM}$.

\section{Measurement}

\section{Physical measurement}

The melting point was measured using a melting point apparatus (model SMP1o Stuart) and taken in an open capillary tube. The molar conductivity values were measured with DMF at room temperature using an SI Analytic Lab 970 conductivity metre at the concentration 2 $\mathrm{x} 10^{-3} \mathrm{M}$. The elemental analysis of synthesised compounds was performed using CHNS/O Model Fision EA 1180 and Thermo Finnigan Flash EA 1112 Series. Meanwhile, the infrared spectra were recorded on a Fourier TransformInfrared Attenuated Total Reflectance (FTIR-ATR) Perkin
Elmer Spectrophotometer. The electronic absorption spectra were recorded on a PG Instrument $\mathrm{T} 8 \mathrm{O} / \mathrm{T} 8 \mathrm{O}+$ spectrophotometer using $1 \mathrm{~cm}$ quartz cuvette with the concentration of samples at $1 \times 10^{-5} \mathrm{M}$ in the 200-60onm region, using DMSO as a solvent. ${ }^{1} \mathrm{H}$ and ${ }^{13} \mathrm{C}$ NMR spectra were measured on a BRUKER spectrophotometer using deuterated dimethyl sulfoxide (DMSO- $\mathrm{d}_{6}$ ) as a solvent and tetramethylsilane as an internal reference.

\section{X-ray crystallographic measurement}

A Bruker Smart APEX CCD area detector diffractometer equipped with graphite monochromatised Mo-Ka $(\lambda=0.71073 \AA)$ was employed for determination of the crystal structure of the complex of about $276 \mathrm{~K}$ (Bruker et al., 2009). Data collection: SMART (Bruker et al., 2008); cell refinement: SAINT (Sheldrick, 2008); data reduction: SAINT; the programme(s) used to solve structure: SHELXTL (Spek, 2009); the programme(s) used to refine structure: SHELXTL (Spek, 2009), molecular graphics: SHELXTL (Spek, 2009) software used to prepare material 
for publication: SHELXTL and PLATON (Spek, 2009).

\section{Weight loss measurement}

This measurement was performed as a gravimetric experiment. The mild steel was polished with emery paper, and then washed with distilled water and acetone. The initial weight of mild steel was measured using an analytical balance. Then, the specimens were immersed in a 10omL beaker containing corrosive acidic solution $(1 \mathrm{M} \mathrm{HCl})$ with and without the addition of the inhibitors at different concentrations. After 24 hours of immersion at room temperature, the specimens were rinsed with distilled water and then dried in a desiccator. The specimens were weighed again as the final weight. The experiment was conducted in triplicate, and the average mass was calculated. The corrosion rate $\left(\mathrm{C}_{\mathrm{RW}}\right)$ and the inhibition efficiency $\left(\eta_{\mathrm{w}}\right)$ were calculated by the following equations (Mourya et al., 2013);

$$
\begin{gathered}
C_{R W}=\frac{\Delta W}{S t} \\
\eta_{\mathrm{W}}=\left(\frac{\mathrm{C}_{\mathrm{RW}}^{\circ}-\mathrm{C}_{\mathrm{RW}}}{\mathrm{C}_{\mathrm{RW}}^{\circ}}\right) \times 100
\end{gathered}
$$

Where;

$\Delta \mathrm{W}$ is weight loss; the weight of specimens before and after immersion

$\mathrm{S}$ is the surface area of the specimen $\left(\mathrm{cm}^{2}\right)$

$\mathrm{t}$ is the immersion time $(\mathrm{h})$

$\mathrm{C}^{\circ} \mathrm{RW}$ and $\mathrm{C}_{\mathrm{RW}}$ are corrosion rates in the absence and presence of inhibitors, respectively

\section{Adsorption isotherm}

The electrochemical process that occurs on mild steel surface can be understood by studying the adsorption characteristics. In order to determine the adsorption characteristics of the inhibitors, the degrees of surface coverage obtained from experimental data by weight loss were fitted into different adsorption isotherms such as Langmuir, Temkin and Frumkin as stated in Equations 4 6 (Andreani et al., 2016). The degree of surface coverage was calculated, as stated in Equation 3 (Xu et al., 2013).

$$
\theta=\frac{\mathrm{C}^{\circ}{ }_{\mathrm{RW}}-\mathrm{C}_{\mathrm{RW}}}{\mathrm{C}_{\mathrm{RW}}^{\circ}}
$$

$$
\text { Langmuir : } \frac{C}{\theta}=\frac{1}{K}+C
$$

$$
\text { Temkin }: \operatorname{Ln}\left[\frac{\mathrm{C}}{\theta}\right]=\operatorname{Ln} \mathrm{K}-\mathrm{g} \theta
$$

$$
\text { Frumkin : }\left[\mathrm{C}\left(\frac{\mathrm{C}}{1-\theta}\right)\right]=\operatorname{Ln} K+g \theta
$$

Where $\theta$ is the surface coverage, $\mathrm{CR}^{\circ}$ and $\mathrm{CR}$ are corrosion rates of the mild steel in the absence and presence of inhibitor respectively, $\mathrm{C}$ is the concentration of inhibitor, $\mathrm{K}$ is the adsorption-desorption equilibrium constant and $g$ is the adsorbate parameter.

\section{RESULTS AND DISCUSSION}

\section{A. Characterisation of Compound}

\section{Physical properties}

The physical properties of the synthesised LH and $\mathrm{BuSn}(\mathrm{L}) \mathrm{Cl}_{2}$, which are yield percentage, colour, melting point, molar conductivity, and elemental percentages are shown in Table 1 . The $\mathrm{BuSn}(\mathrm{L}) \mathrm{Cl}_{2}$ has a higher melting point as compared to the LH. The molar conductivity of the $\mathrm{BuSn}(\mathrm{L}) \mathrm{Cl}_{2}$ is in the range that indicates a non-electrolyte behaviour (Singh et al., 2016). Results of the elemental analysis for $\mathrm{LH}$ and $\mathrm{BuSn}(\mathrm{L}) \mathrm{Cl}_{2}$ agreed with the theoretical values.

$$
\text { 2. FT-IR }
$$

The infrared spectroscopy shows the presence of functional groups, as presented in the proposed structures. A comparison of the functional groups between the $\mathrm{LH}$ and $\mathrm{BuSn}(\mathrm{L}) \mathrm{Cl}_{2}$ is, as shown in Figure 1. In general, the ligand exhibits thione-thiol tautomerism due to the presence of thioamide $-\mathrm{NH}-\mathrm{C}=\mathrm{S}$ functional group in the structure (Chandra et al., 2013). The LH exists in a solid state which is in a thione form because there is no stretching band around $2500-2650 \mathrm{~cm}^{-1}$, which displays S-H vibration (Neto et al., 
2017). The presence of $\mathrm{C}=\mathrm{S}$ in the compound at $1084 \mathrm{~cm}^{-1}$ justifies that the LH exists in thione form.

Table 1. Physical properties and data analysis of $\mathrm{LH}$ and $\mathrm{BuSn}(\mathrm{L}) \mathrm{Cl}_{2}$

\begin{tabular}{|c|c|c|c|c|c|c|c|c|}
\hline \multirow[t]{2}{*}{ Compound } & \multirow{2}{*}{$\begin{array}{l}\text { Percentage } \\
\text { Yield (\%) }\end{array}$} & \multirow[t]{2}{*}{ Colour } & \multirow{2}{*}{$\begin{array}{c}\text { Melting } \\
\text { Points } \\
\text { (oC) }\end{array}$} & \multirow{2}{*}{$\begin{array}{c}\text { Molar } \\
\text { Conductivity } \\
\left(\mathrm{Scm}^{\mathbf{2}} \cdot \mathrm{mol}^{-1}\right)\end{array}$} & \multicolumn{4}{|c|}{$\begin{array}{c}\text { Elemental Analysis (Experimental) } \\
\text { (\%) }\end{array}$} \\
\hline & & & & & $\mathbf{C}$ & $\mathbf{H}$ & $\mathbf{N}$ & $\mathbf{S}$ \\
\hline LH & 88.06 & $\begin{array}{l}\text { Colourless } \\
\text { crystal }\end{array}$ & $127-130$ & - & $\begin{array}{l}54.05 \\
(53.34)\end{array}$ & $\begin{array}{l}6.31 \\
(7.41)\end{array}$ & $\begin{array}{l}25.23 \\
(24.50\end{array}$ & $\begin{array}{l}14.42 \\
(14.67)\end{array}$ \\
\hline $\mathrm{BuSn}(\mathrm{L}) \mathrm{Cl}_{2}$ & 80.43 & $\begin{array}{l}\text { Yellowish } \\
\text { crystal }\end{array}$ & $190-192$ & 17.7 & $\begin{array}{l}35.89 \\
(34.55)\end{array}$ & $\begin{array}{l}4.48 \\
(4.62)\end{array}$ & $\begin{array}{l}11.96 \\
(11.80)\end{array}$ & $\begin{array}{l}6.83 \\
(6.61)\end{array}$ \\
\hline
\end{tabular}

The important stretching band for both compounds, $v\left(\mathrm{C}=\mathrm{N}_{\mathrm{py}}\right)$ appeared at $1580 \mathrm{~cm}^{-1}$ for $\mathrm{LH}$, and upon complexation, it shifted to a lower frequency, at $1557 \mathrm{~cm}^{-1}$. Besides that, stretching band of $v(\mathrm{C}=\mathrm{N})$ was observed at $1527 \mathrm{~cm}^{-1}$ for the $\mathrm{LH}$, and it shifted to $1504 \mathrm{~cm}^{-1}$ in the spectrum of the $\mathrm{BuSn}(\mathrm{L}) \mathrm{Cl}_{2}$ because of the coordination between ligand to the metal ion through the dative bond. Moreover, stretching band of $v(\mathrm{C}=\mathrm{S})$ in the $\mathrm{LH}$ appeared at $1084 \mathrm{~cm}^{-1}$, but it shifted to a lower frequency, which was $1052 \mathrm{~cm}^{-1}$ after complexation because thiolate $\mathrm{S}$ was formed. The LH exhibited two N-H bands at 3349 and $3210 \mathrm{~cm}^{-1}$. Upon complexation, one N-H band remained unchanged, and the other one disappeared in the spectrum of $\operatorname{BuSn}(\mathrm{L}) \mathrm{Cl}_{2}$. A band at $3348 \mathrm{~cm}^{-1}$ of the $\operatorname{BuSn}(\mathrm{L}) \mathrm{Cl}_{2}$ remained unaffected, reflecting the non-involvement of this $\mathrm{N}-\mathrm{H}(1)$ group in coordination and the disappearance of $\mathrm{N}$ $\mathrm{H}(2)$ was due to the thioenolization of $\mathrm{C}=\mathrm{S}$. The shifting of important stretching bands, as mentioned above indicated the coordination of ligand to a metal ion through pyridine $\mathrm{C}=\mathrm{N}$, azomethine $\mathrm{C}=\mathrm{N}$ and thiolate sulphur, $\mathrm{C}-\mathrm{S}$ bond $(\mathrm{Wu}$ et al., 2017).

The coordination between azomethine nitrogen, pyridine nitrogen and thiolate sulphur atoms from the LH to the $\mathrm{Sn}(\mathrm{IV})$ ion can be attested to the presence of bands $\mathrm{v}(\mathrm{M}-\mathrm{N})$ and $v(M-S)$. In the far infrared region, the stretching bands at 336,285 and $354 \mathrm{~cm}^{-1}$ were tentatively assigned to $v(\mathrm{Sn}$ $\mathrm{N}), v\left(\mathrm{Sn}-\mathrm{N}_{\mathrm{py}}\right)$ and $v(\mathrm{Sn}-\mathrm{S})$, respectively. Also, the stretching band at $269 \mathrm{~cm}^{-1}$ was assigned to $\mathrm{v}(\mathrm{Sn}-\mathrm{Cl})$ (Parrilha et al., 2011). In conclusion, the infrared spectra studies showed tridentate of $\mathrm{N}_{\mathrm{py}}-\mathrm{N}-\mathrm{S}$ chelating system with chloride ion and butyl group attached to the metal ion.

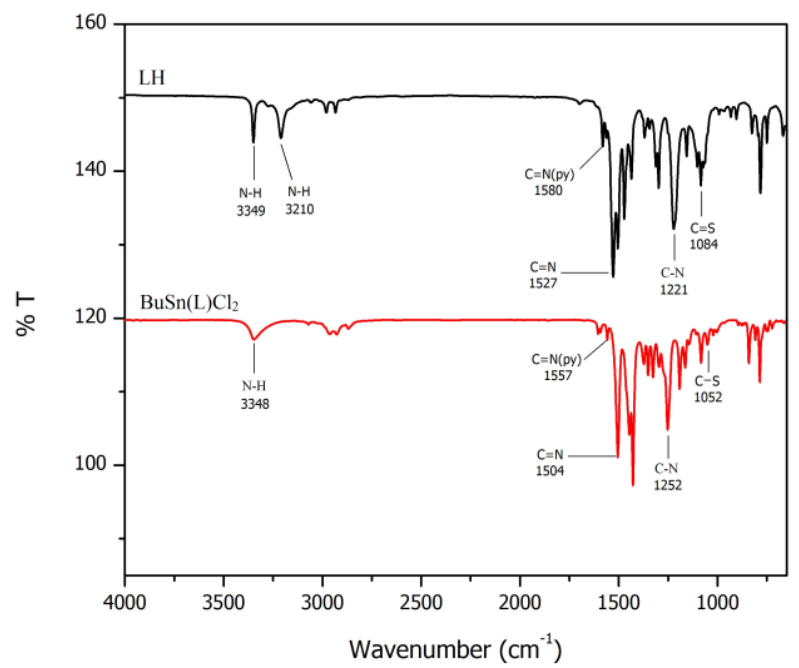

Figure 1. IR spectrum of $\mathrm{LH}$ and $\mathrm{BuSn}(\mathrm{L}) \mathrm{Cl}_{2}$

$$
\text { 3. } U V \text {-Vis }
$$

For UV-Vis analysis, the LH had two absorption peaks which were $\mathrm{n} \rightarrow \pi^{*}$ and $\pi \rightarrow \pi^{*}$, but showed only one absorption peak which was $\pi \rightarrow \pi^{*}(320 n m)$. Since $n \rightarrow \pi^{*}$ was a weak transition, it was expected to overlap with $\pi \rightarrow \pi^{*}$ absorption peak. The absorption peak of $\pi \rightarrow \pi^{*}$ refers to the transition of electrons in the azomethine unit and aromatic ring (Dzulkifli et al., 2015). When the LH coordinated to the metal ion, the transition was shifted to a shorter wavelength at $302 \mathrm{~nm}$, and a new absorption peak appeared at $400 \mathrm{~nm}$ which was assigned to the ligand to metal charge transfer (LMCT) (Salam et al., 2012). As reported by Hosseini-Yazdi et al. (2016), the existence of LMCT was due to the transition of electrons from the lone pair of a nitrogen atom 
to the empty metal ion orbital. The $\mathrm{BuSn}(\mathrm{L}) \mathrm{Cl}_{2}$ underwent a hypsochromic shift. The shifting of wavelength from LH to $\mathrm{BuSn}(\mathrm{L}) \mathrm{Cl}_{2}$ supported the coordination of ligand to tin(IV) ion. The UV-Vis absorption spectra of $\mathrm{LH}$ and $\mathrm{BuSn}(\mathrm{L}) \mathrm{Cl}_{2}$ are as shown in Figure 2.

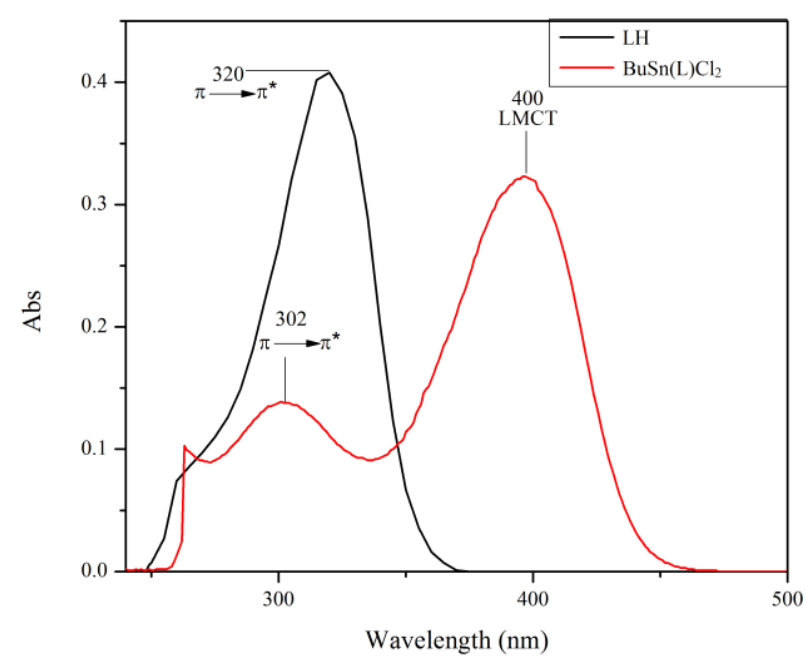

Figure 2. UV-Vis absorption spectra of $\mathrm{LH}$ and $\mathrm{BuSn}(\mathrm{L}) \mathrm{Cl}_{2}$

\section{4. ${ }^{1} \mathrm{H},{ }^{13} \mathrm{C}$ and ${ }^{119} \mathrm{Sn} \mathrm{NMR}$}

${ }^{1} \mathrm{H}$ and ${ }^{13} \mathrm{C}$ NMR data of $\mathrm{LH}$ and $\mathrm{BuSn}(\mathrm{L}) \mathrm{Cl}_{2}$ are tabulated in Tables 2 and 3, respectively. ${ }^{13} \mathrm{C}$ and ${ }^{1} \mathrm{H}$ NMR showed considerable shifting in their chemical shift values from $\mathrm{LH}$ to $\mathrm{BuSn}(\mathrm{L}) \mathrm{Cl}_{2}$. This proved that the coordination occurred through pyridine $\mathrm{C}=\mathrm{N}$, azomethine $\mathrm{C}=\mathrm{N}$ and thiolate sulphur, C-S.

${ }^{1} \mathrm{H}$ NMR spectra of the compounds were assigned based on chemical shifts and multiplicities. The LH exhibited as a thione form approved by the absence of a broad signal at 4.0 $\pm 0.2 \mathrm{ppm}$, which indicated the $\mathrm{SH}$ resonance (Hosseini-Yazdi et al., 2016). $\mathrm{N}(1) \mathrm{H}$ is hydrogen that bonded next to $\mathrm{CH}_{2}$ signal, which appeared as a triplet at $8.68 \mathrm{ppm}$. Meanwhile, $\mathrm{N}(2) \mathrm{H}$ is hydrogen that bonded next to $\mathrm{C}=\mathrm{S}$ signal that appeared as a singlet at $10.25 \mathrm{ppm}$. Upon complexation, the peak of $\mathrm{N}(1) \mathrm{H}$ has shifted to downfield, and $\mathrm{N}(2) \mathrm{H}$ signal has disappeared due to deprotonation of LH when coordinated to the metal ion.

Furthermore, the shifting of the $\mathrm{CH}_{3}-\mathrm{C}=\mathrm{N}$ signal to downfield, which appeared as a singlet in the $\mathrm{BuSn}(\mathrm{L}) \mathrm{Cl}_{2}$ spectrum revealed the involvement of azomethine nitrogen in coordination to the metal ion. The aromatic ring proton signal of the LH was found as multiplets in between 7.36 8.58, which shifted to downfield upon complexation (Abdalla et al., 2015). The butyl group attached to the tin(IV) in $\mathrm{BuSn}(\mathrm{L}) \mathrm{Cl}_{2}$ showed multiplets between 1.18-2.06 ppm.

In ${ }^{13} \mathrm{C}$ NMR, the signals of the carbon atoms attached to the azomethine, $\mathrm{C}=\mathrm{N}_{\text {py }}$ and $\mathrm{CH}_{3}-\mathrm{C}=\mathrm{N}$ in the $\mathrm{LH}$ appeared at 155.17 and $12.59 \mathrm{ppm}$, respectively. Meanwhile, the signals appeared at 145.09 and $14.49 \mathrm{ppm}$, respectively in $\mathrm{BuSn}(\mathrm{L}) \mathrm{Cl}_{2}$. The shifting of $\mathrm{C}=\mathrm{N}_{\mathrm{py}}$ signal to the upfield region and $\mathrm{CH}_{3}-\mathrm{C}=\mathrm{N}$ signal to the downfield region indicated that the azomethine nitrogen had been involved in coordination with the metal ion. Moreover, the signal of the $\mathrm{C}=\mathrm{S}$ group was shifted to the upfield region in $\mathrm{BuSn}(\mathrm{L}) \mathrm{Cl}_{2}$ as compared to LH, which proved that the coordination occurred through $\mathrm{N}=\mathrm{C}-\mathrm{S}-$ to the metal ion. The carbon of the butyl group that was attached to metal ion was observed at 15.09 ppm and 25.49-28.03 ppm for -- $\mathrm{CH}_{3}$-butyl and $-\mathrm{CH}_{2}$ butyl groups, respectively.

The ${ }^{119}$ Sn NMR spectrum, which was procured by a solution spectrum using the cross-polarization technique, displayed only one signal at $-345.02 \mathrm{ppm}$ that indicated the presence of one tin site. The position of the ${ }^{119} \mathrm{Sn}$ signal was in line with the reported value that ranged between -210 and 400 ppm (Rehman et al., 2008). The X-ray crystallographic study was used to prove the pattern of thiosemicarbazone and the number of chloride ions coordinated to tin(IV) ion.

Table 2. ${ }^{1} \mathrm{H}$ NMR spectra data (ppm) of the $\mathrm{LH}$ and $\mathrm{BuSn}(\mathrm{L}) \mathrm{Cl}_{2}$

\begin{tabular}{|l|c|c|c|c|c|c|c|}
\hline \multirow{2}{*}{ Compound } & \multicolumn{7}{|c|}{ Chemical shift, $\delta(\mathrm{ppm})$} \\
\cline { 2 - 8 } & $\mathrm{N}(1) \mathrm{H}$ & $\mathrm{N}(2) \mathrm{H}$ & $-\mathrm{CH}_{3}$ & $\mathrm{CH}_{3}-\mathrm{C}=\mathrm{N}$ & $-\mathrm{CH}_{2}$ & Aromatic & H-butyl \\
\hline $\mathrm{LH}$ & 8.68 & 10.25 & 1.16 & 2.38 & 3.64 & $7.36-8.58$ & - \\
\hline BuSn(L)Cl 2 & 8.84 & - & 0.94 & 2.71 & 3.51 & $8.29-8.84$ & $1.18-2.06$ \\
\hline
\end{tabular}


Table $3 .{ }^{13} \mathrm{C}$ NMR spectra data (ppm) of the $\mathrm{LH}$ and $\mathrm{BuSn}(\mathrm{L}) \mathrm{Cl}_{2}$

\begin{tabular}{|l|c|c|c|c|c|c|c|c|}
\hline \multirow{2}{*}{ Compound } & \multicolumn{7}{|c|}{ Chemical shift, $\delta$ (ppm) } \\
\cline { 2 - 9 } & $\mathrm{C}=\mathrm{S}$ & $\mathrm{C}=\mathrm{N}$ & $-\mathrm{CH}_{3}$ & $\mathrm{CH}_{3} \mathrm{C}=\mathrm{N}$ & $-\mathrm{CH}_{2}$ & Phenyl ring & $-\mathrm{CH}_{3}$-butyl & $-\mathrm{CH}_{2}$-butyl \\
\hline $\mathrm{LH}$ & 178.10 & 155.17 & 14.93 & 12.59 & 39.01 & $121.26-148.93$ & - & - \\
\hline BuSn(L)Cl 2 & 169.13 & 145.09 & 14.12 & 14.49 & 36.18 & $125.56-143.48$ & 15.09 & $25.49-28.03$ \\
\hline
\end{tabular}

\section{B. X-ray Crystallographic Study}

The X-ray crystallographic outcomes proved that the LH served as a tridentate donor, wherein it was coordinated to tin(IV) ion through pyridine nitrogen, azomethine nitrogen, and thiolate sulphur. $\mathrm{LH}$ and $\mathrm{BuSn}(\mathrm{L}) \mathrm{Cl}_{2}$ were crystallised in a monoclinic system with space group $\mathrm{P}_{2} / \mathrm{c}$. This analysis also revealed that the $\mathrm{BuSn}(\mathrm{L}) \mathrm{Cl}_{2}$ exhibited a distorted octahedral geometry that consisted of two 5membered rings, two chloride ions, and a butyl group. The geometry was proven by the following bond angles; N4-SnN3 $\left[72.9(4)^{\circ}\right]$, N3-Sn-S1 $\left[79.0(3)^{\circ}\right]$, S1-Sn-C11 [108.7(5) $\left.{ }^{\circ}\right]$ and $\mathrm{N} 4-\mathrm{Sn}-\mathrm{C} 11\left[99.4(6)^{\circ}\right]$, which deviated from the ideal value of $180^{\circ}$ (Garcia et al., 2017).

Figures 3 and 4 illustrate the molecular structures of LH and $\mathrm{BuSn}(\mathrm{L}) \mathrm{Cl}_{2}$, respectively, along with the atomic numbering scheme. The crystal data and the selected bond distances with bond angles are as presented in Tables 4, 5, and 6 , respectively. The packing diagram(s) viewed down the $a$-axis, as portrayed in Figures 5 and 6 for LH and $\operatorname{BuSn}(\mathrm{L}) \mathrm{Cl}_{2}$, respectively.

The pyridine ring fragment $\left(\mathrm{N}_{1} / \mathrm{C}_{2} / \mathrm{C}_{3} / \mathrm{C}_{4} / \mathrm{C}_{5} / \mathrm{C} 6\right)$ in the LH was planar with maximum deviations of $0.010 \AA$ for $\mathrm{C}$ (5) atoms from the least square plane. Both thiourea $\left(\mathrm{S} 1 / \mathrm{N}_{3} / \mathrm{N}_{4} / \mathrm{C} 9 / \mathrm{C} 10\right)$ and azomethine $\left(\mathrm{N}_{2} / \mathrm{N}_{3} / \mathrm{C} 6 / \mathrm{C} 7 / \mathrm{C} 8\right)$ fragments were also planar with maximum deviations of $0.004 \AA$ for $\mathrm{N}_{4}$ atom and $0.018 \AA$ for $\mathrm{N}_{2}, \mathrm{~N}_{3}$, and $\mathrm{C}_{7}$ atoms from the least square planar, respectively. The pyridine ring and thiourea were essentially co-planar; the dihedral angle between them was $21.15^{\circ}$. Also, the pyridine ring and the azomethine fragment were co-planar; the dihedral angle between them was $16.28^{\circ}$.
The thiourea fragment and the pyridine ring were in a trans configuration concerning imine $\mathrm{C}_{7}=\mathrm{N} 2$. The $\mathrm{C}_{9}-\mathrm{S} 1$ bond distance was $1.6727 \AA$, which was intermediate between the values for the $\mathrm{C}-\mathrm{S}$ bond at $1.82 \AA$ and $\mathrm{C}=\mathrm{S}$ double bond at $1.56 \AA$ (Khalaji et al., 2010).

The pyridine ring fragment $\left(\mathrm{N} 4 / \mathrm{C} 6 / \mathrm{C}_{7} / \mathrm{C} 8 / \mathrm{C} 9 / \mathrm{C} 10\right)$ in $\mathrm{BuSn}(\mathrm{L}) \mathrm{Cl}_{2}$ was planar with maximum deviations of $0.013 \AA$ for $\mathrm{N}_{4}$ atom from the least square plane. The thiourea (S1/N1/N2/C2/C3) was also planar with maximum deviations of $0.0039 \AA$ for $\mathrm{N}_{3}$ atom from the least square plane. The pyridine ring and thiourea were essentially coplanar; the dihedral angle between them was $12.4^{\circ}$. The $\mathrm{C}_{3}-$ S1 bond distance was $1.766 \AA$, which corresponded to a single bond character nearer to the values of the C-S bond at $1.82 \AA$ (Khalaji et al., 2010). The bond distance $\mathrm{C}_{3}-\mathrm{N} 2$ was 1.30(2) A, which accounted for the double bond character and was excluded from coordination to tin(IV) ion. The bond length of Sn-N4 (2.28(1) $\AA$ ) that belonged to $\mathrm{Sn}-\mathrm{N}_{\mathrm{py}}$ was longer than that of $\mathrm{Sn}^{-\mathrm{N}_{3}}$ (2.20(1) $\AA$ ). Moreover, the length of Sn-S1 bond was shorter, as reported for a compound that contained sulphur; $2.44 \AA \AA$ (Teoh et al., 1999).

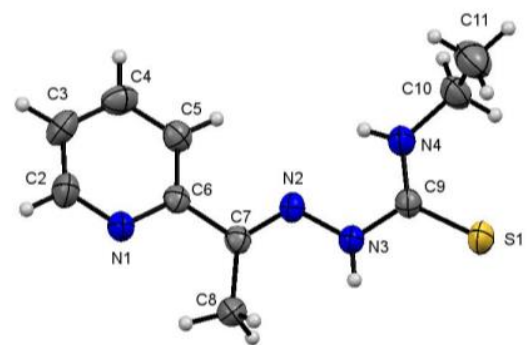

Figure 3. The thermal ellipsoidal plot of LH. Displacement ellipsoids are drawn at the $50 \%$ probability level, and $\mathrm{H}$ atoms are shown as spheres of arbitrary radii 


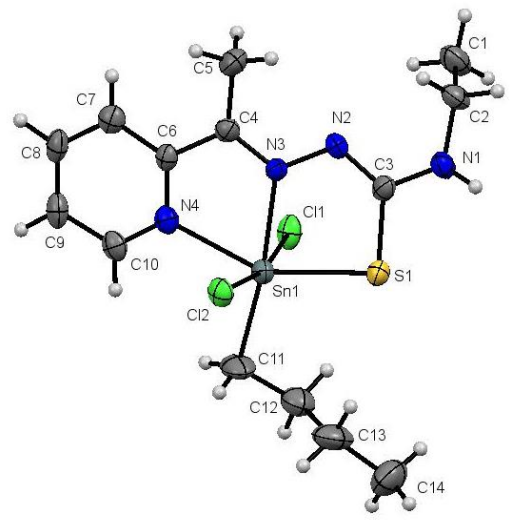

Figure 4. The thermal ellipsoidal plot of $\mathrm{BuSn}(\mathrm{L}) \mathrm{Cl}_{2}$.

Displacement ellipsoids are drawn at the $50 \%$ probability level, and $\mathrm{H}$ atoms are shown as spheres of arbitrary radii

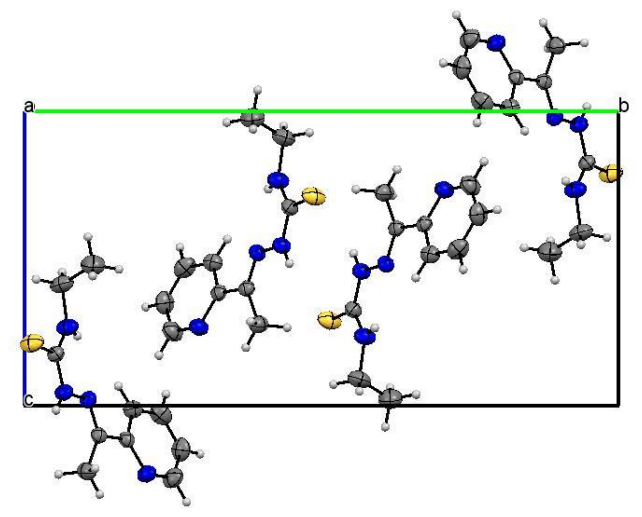

Figure 5. Packing diagram of the LH viewed along the $a$-axis

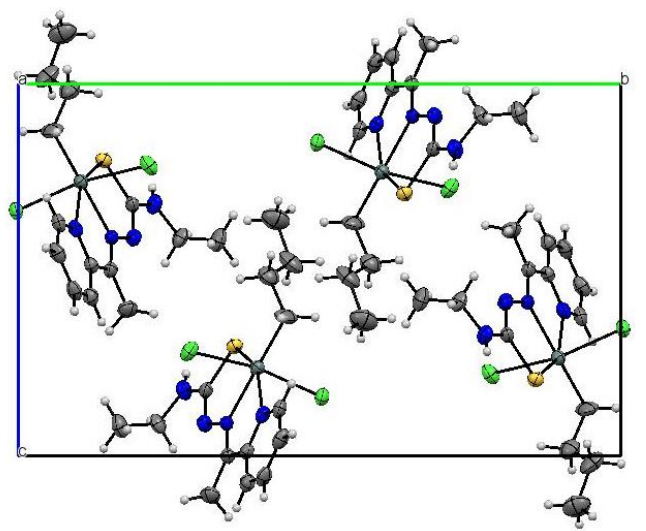

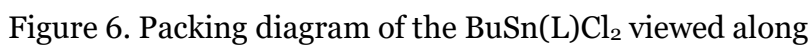
the $a$-axis

Table 4. Experimental data of crystallographic analysis for $\mathrm{LH}$ and $\mathrm{BuSn}(\mathrm{L}) \mathrm{Cl}_{2}$

\begin{tabular}{|l|l|l|}
\hline & \multicolumn{1}{|c|}{$\mathrm{LH}$} & \multicolumn{1}{|c|}{${\mathrm{BuSn}(\mathrm{L}) \mathrm{Cl}_{2}}^{-1}$} \\
\hline Formula & $\mathrm{C}_{10} \mathrm{H}_{14} \mathrm{~N}_{4} \mathrm{~S}$ & $\mathrm{C}_{14} \mathrm{H}_{22} \mathrm{Cl}_{2} \mathrm{~N}_{4} \mathrm{SSn}$ \\
\hline Formula weight & 222.32 & 468.00 \\
\hline Wavelength, Mo Ka $(\AA)$ & 0.71076 & 0.71076 \\
\hline Crystal system & Monoclinic & Monoclinic \\
\hline Space group & $\mathrm{P}_{1} / \mathrm{n}$ & $\mathrm{P} 2_{1} / \mathrm{c}$ \\
\hline$a(\AA)$ & $5.705(9)$ & $7.87(2)$ \\
\hline$b(\AA)$ & $19.94(3)$ & $19.79(5)$ \\
\hline$c(\AA)$ & $9.989(14)$ & $12.46(4)$ \\
\hline$\alpha\left(^{\circ}\right)$ & 90 & 90 \\
\hline$\beta\left(^{\circ}\right)$ & $98.97(7)$ & $101.03(10)$ \\
\hline$\gamma\left({ }^{\circ}\right)$ & 90 & 90 \\
\hline Volume $(\mathrm{V})(\AA 3)$ & $1123(3)$ & $1905(9)$ \\
\hline$Z$ & 4 & 4 \\
\hline Crystal size (mm) & $0.1 \times 0.37 \times 0.5$ & $0.24 \times 0.4 \times 0.53$ \\
\hline F(ooo) & 504.0 & 936 \\
\hline Goodness-of-fit on $F^{2}$ & 1.037 & 1.158 \\
\hline Rint & 0.1300 & 0.1739 \\
\hline & & \\
\hline
\end{tabular}




\begin{tabular}{|l|l|l|}
\hline Theta min & 3.696 & 2.830 \\
\hline Theta max & 28.879 & 28.406 \\
\hline $\begin{array}{l}\text { Final R indices } \\
{[\mathrm{I}>2 \sigma(\mathrm{I})]}\end{array}$ & $\begin{array}{l}\mathrm{R}_{1}=0.0596 \\
\mathrm{wR} \mathrm{R}_{2}=0.1191\end{array}$ & $\begin{array}{l}\mathrm{R}_{1}=0.1016 \\
\mathrm{wR}_{2}=0.2583\end{array}$ \\
\hline $\begin{array}{l}\text { Final R indices } \\
\text { (all data) }\end{array}$ & $\mathrm{R}_{1}=0.1104$ & $\mathrm{R}_{1}=0.1406$ \\
$\mathrm{wR}_{2}=0.1398$ & $\mathrm{wR}_{2}=0.2912$ \\
\hline
\end{tabular}

Table 5. Bond distances of $\mathrm{LH}$ and $\mathrm{BuSn}(\mathrm{L}) \mathrm{Cl}_{2}$

\begin{tabular}{|c|c|c|c|c|c|c|c|}
\hline \multicolumn{8}{|l|}{$\mathbf{L H}$} \\
\hline S1-C9 & 1.6727 & N1-C2 & 1.3284 & $\mathrm{C} 6-\mathrm{C}_{7}$ & 1.4768 & $\mathrm{C}_{7-\mathrm{C} 8}$ & 1.4827 \\
\hline N1-C6 & 1.3374 & $\mathrm{~N}_{2}-\mathrm{N}_{3}$ & 1.3661 & $\mathrm{C}_{4}-\mathrm{C}_{5}$ & 1.3709 & $\mathrm{C}_{5}-\mathrm{C} 6$ & 1.3775 \\
\hline $\mathrm{N}_{2}-\mathrm{C}_{7}$ & 1.2789 & N3-C9 & 1.3559 & $\mathrm{C}_{2}-\mathrm{C}_{3}$ & 1.3589 & $\mathrm{C}_{3}-\mathrm{C}_{4}$ & 1.3681 \\
\hline N4-C9 & 1.3121 & $\mathrm{~N}_{4}-\mathrm{C} 10$ & 1.4600 & C10-C11 & 1.4880 & & \\
\hline \multicolumn{8}{|c|}{$\mathrm{BuSn}(\mathrm{L}) \mathrm{Cl}_{2}$} \\
\hline Sn1-Cl1 & $2.546(6)$ & Sn1-N4 & $2.28(1)$ & $\mathrm{N}_{4}-\mathrm{C} 10$ & $1.30(2)$ & N1-C2 & $1.45(2)$ \\
\hline Sn1-Cl2 & $2.485(6)$ & Sn1-C11 & $2.16(2)$ & $\mathrm{N}_{3}-\mathrm{C}_{4}$ & $1.30(2)$ & N1-C3 & $1.35(2)$ \\
\hline Sn1-S1 & $2.500(6)$ & S1-C3 & $1.77(1)$ & N2-N3 & $1.38(2)$ & C9-C10 & $1.41(2)$ \\
\hline Sn1-N3 & $2.20(1)$ & N4-C6 & $1.34(2)$ & N2-C3 & $1.30(2)$ & & \\
\hline
\end{tabular}

Table 6. Bond angles of $\mathrm{LH}$ and $\mathrm{BuSn}(\mathrm{L}) \mathrm{Cl}_{2}$

\begin{tabular}{|c|c|c|c|c|c|}
\hline \multicolumn{6}{|l|}{ LH } \\
\hline C2-N1-C6 & 117.45 & $\mathrm{~N} 1-\mathrm{C}_{2}-\mathrm{C}_{3}$ & 124.21 & N1-C6-C5 & 121.90 \\
\hline C9-N4-C10 & 125.20 & $\mathrm{C}_{4}-\mathrm{C}_{5}-\mathrm{C} 6$ & 119.08 & $\mathrm{~N} 2-\mathrm{C} 7-\mathrm{C} 6$ & 114.99 \\
\hline $\mathrm{C}_{3}-\mathrm{C}_{4}-\mathrm{C}_{5}$ & 119.27 & $\mathrm{C}_{5}-\mathrm{C} 6-\mathrm{C}_{7}$ & 122.04 & S1-C9-N3 & 120.21 \\
\hline N1-C6-C7 & 116.03 & C6-C7-C8 & 119.15 & $\mathrm{~N}_{4}-\mathrm{C}_{10} \mathrm{-C} 11$ & 113.47 \\
\hline $\mathrm{N} 2-\mathrm{C}_{7}-\mathrm{C} 8$ & 125.82 & $\mathrm{~N}_{3}-\mathrm{C} 9-\mathrm{N} 4$ & 115.71 & & \\
\hline S1-C19-N4 & 124.07 & $\mathrm{~N} 2-\mathrm{N}_{3}-\mathrm{C} 9$ & 118.45 & & \\
\hline $\mathrm{N}_{3}-\mathrm{N} 2-\mathrm{C} 7$ & 119.54 & $\mathrm{C}_{2}-\mathrm{C}_{3}-\mathrm{C}_{4}$ & 118.05 & & \\
\hline \multicolumn{6}{|l|}{$\mathrm{BuSn}_{(\mathrm{L}) \mathrm{Cl}_{2}}$} \\
\hline Cl1-Sn1-Cl2 & $168.6(1)$ & S1-Sn1-N4 & $151.9(3)$ & $\mathrm{N} 2-\mathrm{N}_{3}-\mathrm{C} 4$ & 119(1) \\
\hline Cl1-Sn1-S1 & $94 \cdot 3(1)$ & S1-Sn1-C11 & $108.7(5)$ & Sn1-N4-C6 & $113.7(8)$ \\
\hline Cl1-Sn1-N3 & $85.0(3)$ & N3-Sn1-N4 & $72.9(4)$ & Sn1-N4-C10 & $125.8(9)$ \\
\hline Cl1-Sn1-N4 & $84.1(3)$ & N3-Sn1-C11 & $171.8(6)$ & C6-N4-C10 & $120(1)$ \\
\hline Cl1-Sn1-C11 & $91.3(5)$ & N4-Sn1-C11 & $99.4(6)$ & $\mathrm{N} 1-\mathrm{C} 2-\mathrm{C} 1$ & $113(1)$ \\
\hline Cl2-Sn1-S1 & 93.1(1) & Sn1-S1-C3 & 94.9(4) & $\mathrm{S}_{1}-\mathrm{C}_{3}-\mathrm{N} 1$ & $115.5(9)$ \\
\hline Cl2-Sn1-N3 & $87.9(3)$ & $\mathrm{C}_{2}-\mathrm{N} 1-\mathrm{C}_{3}$ & 122(1) & $\mathrm{S}_{1}-\mathrm{C}_{3}-\mathrm{N}_{2}$ & $128(1)$ \\
\hline Cl2-Sn1-N4 & $85 \cdot 3(3)$ & $\mathrm{N}_{3}-\mathrm{N} 2-\mathrm{C}_{3}$ & $116(1)$ & $\mathrm{N}_{1}-\mathrm{C}_{3}-\mathrm{N} 2$ & $117(1)$ \\
\hline Cl2-Sn1-C11 & 94.5(5) & Sn1-N3-N2 & 121.1(7) & $\mathrm{N}_{3}-\mathrm{C}_{4}-\mathrm{C}_{5}$ & 121(1) \\
\hline S1-Sn1-N3 & $79.0(3)$ & Sn1-N3-C4 & $119.5(8)$ & & \\
\hline
\end{tabular}




\section{Corrosion Inhibition Study}

\section{Weight loss experiment}

The values obtained from the weight loss experiment for both inhibitors, $\mathrm{LH}$ and $\operatorname{BuSn}(\mathrm{L}) \mathrm{Cl}_{2}$, at various concentrations are tabulated in Table 7 . Figure 7 illustrates the outcomes of inhibition efficiency (in \%) for both inhibitors. The results indicated that $\mathrm{BuSn}(\mathrm{L}) \mathrm{Cl}_{2}$ exerted higher inhibition efficiency when compared to LH. The higher inhibition efficiency of the tin complex is on account of its higher adsorptive capability due to the presence of additional active sites on the complex, and also, in part, due to the effects of its increased size and molecular weight (Keles et al., 2015). This contributes to the build-up of a more protective film of adsorbed molecules on the metal surface that lessens the corrosive action of the acidic test medium. For both the ligand and the organotin complex, inhibition efficiency increased with concentration; the efficiency was as high as $98.98 \%$ with $3 \mathrm{mM}$ concentration for the complex. Although other organotins have previously been investigated as corrosion inhibition agents for mild steel, their efficiency has not achieved such maximal levels as noted for the title compound applied in this study (Hadi et al., 2015; Rastogi et al., 2011, Singh et al., 2010).

A similar trend was reported by Rastogi et al., (2005), wherein the inhibition efficiency of dibutyltin complex exhibited high inhibition efficiency, in comparison to that of the ligand. Ligand, 1-phenyl-2,5dithiohydrazodicarbonamide, and their dibutyltin complex exerted maximum inhibition efficiency at $100 \mathrm{ppm}$, which were $72.87 \%$ and $79.80 \%$, respectively. Also, the inhibition efficiency reported by $\mathrm{Xu}$ et al. (2013) for compound 3pyridinecarboxaldehyde thiosemicarbazone showed maximum inhibition efficiency at $97 \%$ with $1.5 \mathrm{mM}$. Although the reported ligand showed high inhibition efficiency, as compared to ligand, LH; the synthesised complex, $\mathrm{BuSn}(\mathrm{L}) \mathrm{Cl}_{2}$, displayed better inhibition efficiency.

Table 7. Corrosion inhibition data

\begin{tabular}{|c|c|c|c|c|c|}
\hline Inhibitor & Concentration (mM) & $\Delta \mathbf{W}$ & CR (mg.cm-2h $\left.{ }^{-1}\right)$ & $\boldsymbol{\theta}$ & $\eta_{w}(\%)$ \\
\hline Blank & $1 \mathrm{M}$ & 0.177 & $1.475 \times 10^{-3}$ & - & - \\
\hline \multirow{5}{*}{$\mathrm{LH}$} & 1.0 & 0.0221 & $1.842 \times 10^{-4}$ & 0.8751 & 87.51 \\
\hline & 1.5 & 0.0217 & $1.808 \times 10^{-4}$ & 0.8774 & 87.74 \\
\hline & 2.0 & 0.018 & $1.500 \times 10^{-4}$ & 0.8983 & 89.83 \\
\hline & 2.5 & 0.015 & $1.250 \times 10^{-4}$ & 0.9153 & 91.53 \\
\hline & 3.0 & 0.014 & $1.167 \times 10^{-4}$ & 0.9209 & 92.09 \\
\hline \multirow{5}{*}{$\operatorname{BuSn}(\mathrm{L}) \mathrm{Cl}_{2}$} & 1.0 & 0.0043 & $3.583 \times 10^{-5}$ & 0.9757 & 97.57 \\
\hline & 1.5 & 0.0035 & $2.916 \times 10^{-5}$ & 0.9802 & 98.02 \\
\hline & 2.0 & 0.0033 & $2.750 \times 10^{-5}$ & 0.9814 & 98.14 \\
\hline & 2.5 & 0.0027 & $2.250 \times 10^{-5}$ & 0.9847 & 98.47 \\
\hline & 3.0 & 0.0018 & $1.500 \times 10^{-5}$ & 0.9898 & 98.98 \\
\hline
\end{tabular}




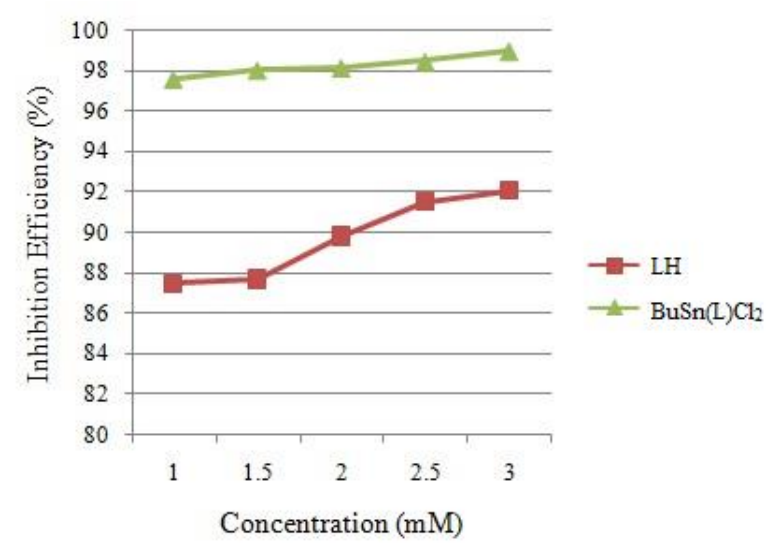

Figure 7. Inhibition efficiency of $\mathrm{LH}$ and $\mathrm{BuSn}(\mathrm{L}) \mathrm{Cl}_{2}$

\section{Adsorption isotherm behaviour}

The plots illustrated in Figure 8 refer to Langmuir isotherms for adsorption of $\mathrm{LH}$ and $\mathrm{BuSn}(\mathrm{L}) \mathrm{Cl}^{2}$. Varying adsorption isotherms were attempted to fit the $\theta$ values in seeking a suitable adsorption isotherm, and by far, Langmuir's adsorption isotherm emerged as the best description of the adsorption behaviour of both compounds on the mild steel surface. The straight line gave the values

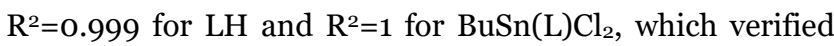
the suitability of this isotherm (John et al., 2017). These results indicated that the inhibitors were adsorbed on the mild steel by monolayer and through a physical mechanism (Hashim et al., 2012). Based on the Langmuir isotherm model, it is assumed that the mild steel surface could hold one adsorbed species per adsorption site since the adsorption site only occupied a fixed number of adsorption species without any interaction with other adsorbed species (Zarrok et al., 2011). Furthermore, this isotherm stated that the surface coverage of inhibitor molecules on mild steel increased with increment in inhibitor concentrations (Meena et al., 2018).

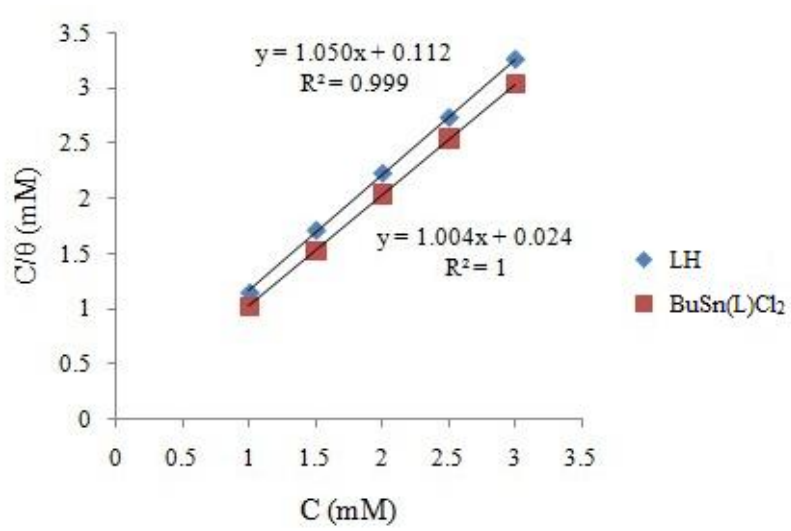

Figure 8. Langmuir isotherm for the adsorption of LH and $\mathrm{BuSn}(\mathrm{L}) \mathrm{Cl}_{2}$

\section{CONCLUSION}

The ligand $\mathrm{LH}$ and it's tin(IV) complex, $\mathrm{BuSn}(\mathrm{L}) \mathrm{Cl}_{2}$ were successfully synthesised and elucidated by elemental analysis, FT-IR, UV-Vis, molar conductivity, ${ }^{1} \mathrm{H},{ }^{13} \mathrm{C}$, and ${ }^{119}$ Sn NMR spectra studies. This paper also reported the molecular structure of the ligand and complex that were confirmed by X-ray crystallographic studies. LH and $\mathrm{BuSn}(\mathrm{L}) \mathrm{Cl}_{2}$ showed the potential to be used as corrosion inhibitors on mild steel in $1 \mathrm{M} \mathrm{HCl}$ by conducting weight loss measurement and adsorption isotherm study. $\mathrm{BuSn}(\mathrm{L}) \mathrm{Cl}_{2}$ showed a better inhibition efficiency rather than LH and both inhibitors obeyed Langmuir's adsorption isotherm.

\section{ACKNOWLEDGMENT}

This work was supported by the research grant from the Ministry of Higher Education, with grant number FRGS/1/2016/STGo1/UITM/03/6. The authors would like to express their gratitude to the Faculty of Applied Sciences, Universiti Teknologi MARA Shah Alam, Faculty of Applied Sciences, Universiti Teknologi MARA Negeri Sembilan, Faculty of Science and Technology and the Centre of Research and Instrumentation (CRIM), Universiti Kebangsaan Malaysia for the research facilities provided. 


\section{REFERENCES}

[1] Abdalla, O, Farina, Y \& Ibrahim, N 2015, 'Synthesis, characterization and antibacterial study of copper(II) complexes of thiosemicarbazones', The Malaysian Journal of Analytical Sciences, vol. 19, no. 6, pp. 1171-1178.

[2] Abu-Dief, AM \& Mohamed, IMA 2015, 'A review on versatile applications of transition metal complexes incorporating Schiff bases', Beni-Suef University Journal of Basic Applied Sciences, vol. 4, pp. 1-15.

[3] Al-Amiery, AA, Kadhum, AAH, Mohamad, AB \& Junaedi, S 2013, 'A novel hydrazinecarbothioamide as a potential corrosion inhibitor for mild steel in HCl', Materials, vol. 6, no. 4, pp. 1420-1431.

[4] Ameer, MA, Khamis, E \& Al-Senani, G 2000, 'Adsorption studies of the effect of thiosemicarbazides on the corrosion of steel in phosphoric acid', Adsorption Science and Technology, vol. 18, no. 3, pp. 177-194.

[5] Andreani, S, Znini, M, Paolini, J, Majidi, L, Hammouti, B, Costa, J \& Muselli, A 2016, 'Study of corrosion inhibition for mild steel in hydrochloric acid solution by Limbarda Crithmoides (L.) essential oil of Corsica', Journal of Material Environment Science, vol. 7, no. 1, pp. 187-195.

[6] Badr G.E 2009, "The role of some thiosemicarbazide derivatives as corrosion inhibitors for C-steel in acidic media', Corrosion Science, vol. 51, no. 11, pp. 2529-2536.

[7] Benhiba, F, Lotfi, N, Ourrak, K, Benzekri, Z, Zarrok, H, Guenbour, A, Souizi, A, El Hezzat, M, Warad, I, Touir, R, Zarrouk, A \& Oudda, H 2017, Corrosion inhibition study of $2-\left(2,4^{-}\right.$ dichlorophenyl)-6-Nitro-1, 4- dihydroquinoxaline for carbon steel in hydrochloric acid solution', Journal of Material Environmental Science, vol. 8, no. 11, pp. $3834-3843$.

[8] Bisceglie, F, Monte, GD, Tarasconi, P \& Pelosi, G 2015, 'Synthesis and characterization of 4fluorobenzaldehyde thiosemicarbazone derivatives as corrosion inhibitors', Inorganica Chimica Acta, vol. 434, pp. 143-149.

[9] Bruker SMART, SAINT, SADABS 2009, Bruker AXS Inc., Madison, Wisconsin, USA

[10] Bruker, APEX2, SAINT, SADABS 2008, Bruker AXS Inc., Madison, WI

[11] Chandra, S, Bargujar, S, Nirwal, R \& Yadav, N 2013, 'Synthesis, spectral characterization and biological evaluation of copper(II) and nickel(II) complexes with thiosemicarbazones derived from a bidentate Schiff base', Spectrochimica Acta A: Molecular and Biomolecular Spectroscopy, vol. 106, pp. 9198.

[12] Dzulkifli, NN, Farina, Y \& Yamin, BM 2015, 'Dysprosium(III) isatin 2-methyl-3thiosemicarbazone: Synthesis, structural and characterization', The Malaysian Journal of Analytical Sciences, vol. 19, no. 3, pp. 541-549.

[13] Ebenso, EE, Isabirye, DA \& Eddy, NO 2010, Adsorption and quantum chemical studies on the inhibition potentials of some thiosemicarbazides for the corrosion of mild steel in acidic medium', International Journal of Molecular Sciences, vol. 11, no. 6, pp. 2473-2498.

[14] Ekpe, UJ, Ibok, U J, Ita, BI, Offiong, OE, \& Ebenso, EE 1995. Inhibitory action of methyl and phenyl thiosemicarbazone derivatives on the corrosion of mild steel in hydrochloric acid, Materials Chemistry \& Physics, vol. 40, no. 2, pp. 87-93.

[15] Elemike, EE, Onwudiwe, DC, Nwankwo, HU \& Hosten EC 2017, Synthesis, crystal structure, electrochemical and anti-corrosion studies of Schiff base derived from o-toluidine and ochlorobenzaldehyde', Journal of Molecular Structure, vol. 1136, pp. 253-262.

[16] Garcia, CV, Parrilha, GL, Rodrigues, BL, Barbeira, PJS, Clarke, RM, Storr, T \& Beraldo, H 2017, 'Cobalt(III) complexes with 2-acetylpyridinederived Schiff bases: Studies investigating ligand 
release upon reduction', Polyhedron, vol. 124, no. 3, pp. 86-95

[17] Goulart, CM, Esteves-Souza, A, Martinez-Huitle, CA, Rodrigues, CJF, Maciel, MAM \& Echevarria A 2013, 'Experimental and theoretical evaluation of semicarbazones and thiosemicarbazones as organic corrosion inhibitors', Corrosion Science, vol. 67, pp. 281-291.

[18] Hadi, S, Afriyani, H, Anggraini, DW, Qudus, IH \& Suhartati, T 2015, 'Synthesis and potency study of some dibutyltin(IV) dinitrobenzoate compounds as corrosion inhibitor for mild steel HRP in DMSO-HCl solution', Asian Journal of Chemistry, vol. 27 , no. 4 , pp. 1509-1512.

[19] Hashim, NZN, Kassim, K \& Mohd, Y 2012, '(E)-N1(4-chlorobenzylidene)-N4-phenylbenzene-1,4diamine as mild steel corrosion inhibitor in $1 \mathrm{M}$ HCl', APCBEE Procedia, vol. 3, pp. 239-244.

[20] Hosseini-Yazdi, SA, Hosseinpour, S, Khandar, AA \& White J 2016, 'Synthesis, characterization, and X-ray crystal structures of copper(II) and nickel(II) complexes with two bis(thiosemicarbazone) ligands and investigation of their electrochemical behavior', Transition Metal Chemistry, vol. 41, no.1, pp. 65-75.

[21] Ismail, A \& Adan, NH 2014, 'Effect of oxygen concentration on corrosion rate of carbon steel in seawater', American Journal of Engineering Research, vol. 3, no. 1, pp. 64-67.

[22] John, S, Jeevana, R, Aravindakshan, KK \& Joseph, A 2017, 'Corrosion inhibition of mild steel by N(4)substituted thiosemicarbazone in hydrochloric acid media', Egyptian Journal of Petroleum, vol. 26, pp. 405-412.

[23] Keles, H, Emir, DM \& Keles, M 2015, 'A comparative study of the corrosion inhibition of low carbon steel in $\mathrm{HCl}$ solution by an imine compound and its cobalt complex', Corrosion Science, vol. 101, pp. 19-31.

[24] Khalaji, AD, Grivani, G, Akerdi, SJ, Gotoh, K, Ishida, H \& Mighani H 2010, 'Synthesis, spectroscopic characterization, crystal structures, and theoretical studies of (E)-2-(2,4- dimethoxybenzylidene)thiosemicarbazone and (E)2-(2,5-dimethoxybenzylidene) thiosemicarbazone', Structural Chemistry, vol. 21, no. 5, pp. 995-1003.

[25] Khaled, KF, Elhabib, OA, El-mghraby, A, Ibrahim, OB \& Ibrahim, MAM 2010, 'Inhibitive effect of thiosemicarbazone derivative on corrosion of mild steel in hydrochloric acid solution', Journal of Material Environmental Science, vol. 1, no. 3, pp. 139-150.

[26] Khan, G, Basirun, WJ, Kazi, SN, Ahmed, P, Magaji, L, Ahmed, SM, Khan, GM \& Rehman, MA 2017, 'Electrochemical investigation on the corrosion inhibition of mild steel by Quinazoline Schiff base compounds in hydrochloric acid solution', Journal of Colloid and Interface Science, vol. 502, pp. 134145 .

[27] Kurniasih, H, Nurissalam, M, Iswantoro, B, Afriyani, H, Qudus, HI \& Hadi, S 2015, "The synthesis, characterization and comparative anticorrosion study of some organotin(IV) 4chlorobenzoates', Oriental Journal of Chemistry, vol. 31, no. 4, pp. 2377-2383.

[28] Manivel, A, Ramkumar, S, Wu, JJ, Asiri, AM \& Anandan, S 2014, 'Exploration of (S)-4,5,6,7tetrahydrobenzo[d]thiazole-2,6-diamine as feasible corrosion inhibitor for mild steel in acidic media', Journal of Environmental Chemical Engineering, vol. 2, pp. 463-470.

[29] Manju, Kishore, D \& Kumar, D 2011, 'Cadmium and tin complexes of Schiff-base ligands', Journal of Coordination Chemistry, vol. 64, no. 12, pp. 2130-2156.

[30] Meena, L, Choudhary P, Varshney AK, Varshney S 2018. 4-ethylcyclohexanonethiosemicarbazone as corrosion inhibitor for iron metal in $0.5 \mathrm{~N}$ hydrochloric acid solution', International Journal of ChemTech Research, vol. 11, no. 7, pp. 337-346.

[31] Mourya, P, Banerjee, S, Rastogi, RB \& Singh, MM 2013, 'Inhibition of mild steel corrosion in hydrochloric and sulfuric acid media using a thiosemicarbazone derivative', Industrial and Engineering Chemical Research, vol. 52, no. 36, pp. 
$12733-12747$.

[32] Neha, Yadav, K, Varshney, S \& Varshney, AK 2015, 'Synthesis, structural and antimicrobial studies of some new tin(II) complexes with semicarbazones and thiosemicarbazones', World Journal of Pharmacy and Pharmaceutical Science, vol. 4, no. 4, pp. 1236-1246.

[33] Neto, LNA, Lima, MCA, Oliveira, JF, Souza, ER, Buonafina, MDS, Anjos, MNV, Brayner, FA, Alves, LC, Neves, RP \& Mendonca-Junior, FJB 2017, 'Synthesis, cytotoxicity and antifungal activity of 5nitro-thiophene-thiosemicarbazones derivatives', Chemico-Biological Interaction, vol. 272, pp. 172181.

[34] Parrilha, GL, Silva, JG, Gouveia, LF, Gasparoto, AK, Dias, RP, Rocha, WR, Santos, DA, Speziali, NL \& Beraldo H 2011, 'Pyridine-derived thiosemicarbazones and their tin(IV) complexes with antifungal activity against Candida spp', European Journal of Medical Chemistry, vol. 46, no. 5, pp. $1473-1482$.

[35] Rastogi, RB, Singh, K \& Maurya, JL 2012, 'Synthesis and characterization of organotin(IV) thiobiurets', Synthesis and Reactivity in Inorganic, Metal-Organic, and Nano-Metal Chemistry, vol. 42, no. 4, pp. 616-620.

[36] Rastogi, RB, Singh, MM, Singh, K, Yadav, M 2005. Organotin dithiohydrazodicarbonamides as corrosion inhibitors for mild steel-dimethyl sulphoxide containing $\mathrm{HCl}$, Portugaliae Electrochimica Acta, vol. 23, pp. 315-332.

[37] Rastogi, RB, Singh, MM, Singh, K, Yadav, M, 2011. Organotin dithiobiurets as corrosion inhibitors for mild steel-dimethyl sulfoxide containing $\mathrm{HCl}$, African Journal of Pure and Applied Chemistry, vol. 5, no. 2, pp. 19-33.

[38] Rehman, W, Baloch, MK \& Badshah, A 2008, 'Synthesis, spectral characterization and bioanalysis of some organotin(IV) complexes', European Journal of Medicinal Chemistry, vol. 43 , no. 11 , pp. $2380-2385$

[39] Reis, CMD, Pereira, DS, Paiva, RDO, Kneipp, LF \&
Echevarria, A, 'Microwave-assisted synthesis of new N1, N4-substituted thiosemicarbazones', Molecules, vol. 16, no. 12, pp. 10668-10684.

[40] Salam, MA, Affan, MA, Saha, R, Ahmad, FB \& Sam $\mathrm{N}$ 2012, 'Synthesis, characterization and in vitro antibacterial studies of organotin(IV) complexes with 2-hydroxyacetophenone-2methylphenylthiosemicarbazone

(H2dampt)', Bioinorganic Chemistry and Application, vol. 2012, pp. 1-9.

[41] Sheldrick, G. M 2008, A short history of SHELX, Acta Crystal, A64, pp. 112-122.

[42] Singh, AK \& Bhandari, S 2003, 'Tin(II and IV) complexes with nitrogen ligands: Review of recent developments', Main Group Metal Chemistry, vol. 26, no. 3, pp. 155-211.

[43] Singh, HL, Singh, JB \& Bhanuka, S 2016, 'Synthesis, spectral, DFT, and antimicrobial studies of tin(II) and lead(II) complexes with semicarbazone and thiosemicarbazones derived from (2hydroxyphenyl)(pyrrolidin-1-yl)methanone',

Journal of Coordination Chemistry, vol. 69, no. 2, pp. $343-353$.

[44] Singh, R, Chaudhary, P \& Kaushik, NK 2010, 'A review: Organotin compounds in corrosion inhibition', Reviews in Inorganic Chemistry, vol. 30, no. 4, pp. 275-294.

[45] Singh, RN \& Singh, VB 1993, 'Corrosion behavior and inhibitive effects of organotin compounds on nickel in formic acid', Corrosion, vol. 49, no. 7, pp. $569-575$.

[46] Spek, A. L 2009, 'Structure validation in chemical crystallography', Acta Crystal D, vol. 65, pp. 148155 .

[47] Teoh, SG, Ang, SH, Fun, HK \& Ong, CW 1999, 'Synthesis, crystal structure and biological activity of thiophene-2-carboxaldehyde thiosemicarbazone and its tin complexes', Journal of Organometallic Chemistry, vol. 580, no. 1, pp. 17-21.

[48] Umoren, SA \& Solomon, MM 2017, Synergistic corrosion inhibition effect of metal cations and mixtures of organic compounds: A Review', 
Journal of Environmental Chemical Engineering, vol. 5, pp. 246-273.

[49] Wu, YY, Wang, YT, Wang, YY, Li, MX, Lu, YL \& Zhang, YH 2017, 'Dimethyltin(IV) and palladium(II) complexes derived from 2benzoylpyridine $\mathrm{N}(4)-$ cyclohexylthiosemicarbazone: Synthesis, crystal structures and biological evaluation', Inorganic Chemical Communication, vol. 78, pp. 65-69.

[50] Xu, B., Liu, Y., Yin, X., Yang, W \& Chen, Y 2013, 'Experimental and theoretical study of corrosion inhibition of 3-pyridinecarbozalde thiosemicarbazone for mild steel in hydrochloric acid', Corrosion Science, vol. 74, pp. 206-213.

[51] Yadav, M, Behera, D \& Kumar, S 2014, 'Experimental and theoretical studies on corrosion inhibition of mild steel in hydrochloric acid by thiosemicarbazone of Schiff bases', Canadian Institute of Mining, Metallurgy and Petroleum, vol. 53, no. 2, pp. 220-231.

[52] Zaferani, SH, Sharifi, M, Zaarei, D \& Shishesaz, MR 2013, Application of eco-friendly products as corrosion inhibitors for metals in acid pickling processes - A review', Journal of Environmental Chemical Engineering, vol.1, pp.652-657.

[53] Zarrok, H, Oudda, H \& Zarrouk, A 2011, 'Weight loss measurement and theoretical study of new pyridazine compound as corrosion inhibitor for C38 steel in hydrochloric acid solution', Der Pharma Chemica, vol. 3, no. 6, pp. 576-590.

[54] Zhang, HH, Zhang, Y \& Yang, Z 2014, 'Investigation of 4-methoxysalicylaldehyde thiosemicarbazone as inhibitor for carbon steel in sulfuric acid solution', Applied Mechanics and Materials, vol. 633-634, pp. 513-516. 